\title{
Optimal Ordering policies of a Two Echelon Supply Chain for Deteriorating Items
}

\author{
Srinivasa Rao $Y$ \\ St. Theressa inst.of engg. \& tech. \\ Garividi,Vizianagaram(Dist), \\ India.
}

\author{
Srinivasa Rao K., \\ Department of Statistics \\ Andhra University \\ Visakhapatnam,India
}

\author{
Kesava Rao V.V.S. \\ Dept. of Mechanical Engineering \\ Andhra University \\ Visakhapatnam,India
}

\begin{abstract}
Supply chain management is a crucial task of managing large organizations. In a decentralized supply chain each member focuses on maximizing his own profit. As a result of it, the conflict between the manufacturer and the retailers will arise. To avoid this sort of situations, coordination model strike a balancing between the profit of manufacturers and retailers. This paper investigates a two echelon supply chain system which consisting of one manufacturer and multiple retailers. Using the mathematical modeling a coordination model which maximizes the total profit is developed and analyzed for deteriorating items. The optimal pricing and ordering policies of the model are also derived. A sensitivity analysis with respect to the parameters and costs is also presented. This model lower down the total cost of supply chain and increases the general profit. It also improves cooperation for both manufacturer and retailer.
\end{abstract}

\section{Key words}

Supply chain, Coordination Model, EOQ, EPQ.

\section{INTRODUCTION}

In this present competitive business environment, Supply Chain Management plays a dominant role due to its ready applicability in many practical situations arising at places like production processes, ware houses, market yards etc.,

In manufacturing and production processes the inventory control is very important. Hence several inventory models have been developed and analyzed independently for manufactures and retailers through EPQ and EOQ models respectively. These models are widely used for several inventory systems if we consider the retailer's inventory is independent of manufacturers inventory Goyal \& Giri (2001), Abdullah Eroglu (2007), J. Gutierrez (2008).

In developing these EOQ or EPQ models the life time of the commodity is considered to be very important. Different inventory models for deteriorating items for single echelon are developed by various researchers. However, in a decentralized supply chain if each member focuses on maximizing his own profit it will conflict the efficiency of the supply chain since the inventory levels of retailers and the producers have interdependence. Taking this into consideration, coordination models of supply chain are developed. v) Replenishments are instantaneous, and the lead-time is assumed to Recently to utilize the resources more effectively Cachon G.P. be negligible.

(2002) has reviewed on setting supply chain coordinating contracts.

In coordination models for supply chain vendor managed inventory strategy, quantity flexibility scheme, discount scheme, return policies etc., became popular (Xuxia Zou,Shaligram pokharel (2008),Cachon.G.P (2004), Weng.Z. K,Wong. R.T (1993), Zhao Quanwu (2005),Chung-Chi Hsieh (2008) recently Liao Li,Wu Yaohua(2008) developed a coordination model of supply chain for deteriorating items using price discount policy and $\mathrm{Yu}, \mathrm{Y}$., Huang, G.Q., \& Liang, L. (2009), Yao, Y., Dong, Y., \& Dresner, M. (2010) developed supply chain under vendor managed inventory. They assumed that the rate of deterioration is constant and demand is also constant for retailers. However, in many practical situations dealing with food processing industries the demand is a function of time at retailer's level. The influence of time on demand can be characterized through a power pattern.

\begin{abstract}
The power pattern demand includes several types of demand including constant rate, increasing and decreasing rates depending up on the pattern index. Hence, in this paper a two echelon supply chain model is developed with the assumption that there is one manufacturer and multiple retailers. By maximizing the system total profit under coordination of manufacturer and retailers through the price discount model proposed by Abdullah Eroglu (2007). Here it is assumed that the demand rate at retailer's level is a function of time and follows a power pattern. It is also further assumed that the life time of commodity is random and having exponential distribution. The optimal operating policies of the Supply Chain are derived and analyzed.
\end{abstract}

\section{ASSUMPTIONS AND NOTATIONS}

The mathematical model is developed based on the following assumptions:

i) One manufacturer and $n^{1}$ retailer are considered for a single product, and the retailers have the same characteristics.

ii) The manufacture production is a typical Make to order production mode.

iii) The demand rate at any time " $t$ " is

$$
\frac{r t^{\frac{1}{n}-1}}{n T^{\frac{1}{n}}}
$$

Where ' $r$ ' is the fixed quantity, $\mathrm{n}$ is the parameter of power demand pattern, the value of $\mathrm{n}$ may be any positive number. $\mathrm{T}$ is the planning horizon.

v) Shortages are allowed for the retailers, and the unsatisfied demand (due to shortages) is completely backlogged.

vi) In the retailer's on-hand inventory, deterioration occurs once the item is bought. Deterioration rate is a known constant, and the deteriorated units are not replaced.

vii) The manufacture production rate is finite and constant. It is unaffected by the lot size. 
viii) Shortage is not allowed for the manufacture. Therefore manufacturer's production rate is greater than the demand rate and the number of units deteriorated per unit time.

ix) For the retailers, the inventory holding cost per unit per unit time, the ordering cost per replenishment, the disposal cost of amelioration per unit, the shortage cost per unit, the purchase cost per unit are known and constant. For the manufacture, the holding cost per unit per unit time, the setup cost per replenishment, and the item cost per unit are known and constant.

We use the following notation throughout the paper:

$n^{1}$ number of retails

$\theta \quad$ The constant deterioration rate, $0<\theta<1$

$\mathrm{k}$ Price discounting coefficient

Manufacturer's production rate,

$P_{S}>n^{1}\left(\frac{r t^{\frac{1}{n}-1}}{n T^{\frac{1}{n}}}\right)$

$\mathrm{C}_{\mathrm{m}}$ Manufacturer's production cost per unit

B Transaction price per unit between Retailer and Consumers

A Transaction price per unit between manufacturer and retailers without cooperation, $\mathrm{C}_{\mathrm{m}} \leq \mathrm{A} \leq \mathrm{B}$

$\mathrm{P}$ Transaction price per unit between manufacturer and retailers under coordination, $\mathrm{C}_{\mathrm{m}} \leq \mathrm{P} \leq \mathrm{B}$

$\mathrm{h}_{\mathrm{r}} \quad$ Retailer's inventory holding cost per unit per unit time

$\mathrm{h}_{\mathrm{s}} \quad$ Manufacturer's inventory holding cost per unit per unit time

$\mathrm{C}_{\mathrm{s}} \quad$ Manufacturer's setup cost per order Cycle

$\mathrm{C}_{\mathrm{rl}} \quad$ Retailer's backlog cost per unit

$\mathrm{C}_{\mathrm{rd}}$ Retailer's disposal cost for Deteriorating items per unit

$\mathrm{C}_{\mathrm{ro}}$ Retailer's ordering cost per order cycle

$\mathrm{T}$ Length of the retailer's replenishment cycle

$\mathrm{T}_{\mathrm{s}} \quad$ Length of the manufacturer's production cycle

$\mathrm{I}(\mathrm{t})$ Retailer's finished goods inventory level at any time $\mathrm{t}$

$t_{1} \quad$ Time of the inventory level decreased to zero, $t_{1} \in[0, T]$

$t_{s} \quad$ Length of the manufacturer's production period

$\mathrm{n}_{\mathrm{s}} \quad$ The manufacturer's ordering times during a production period

S Retailer's inventory shortage quantity during an ordering cycle

$\mathrm{Q}_{\mathrm{r}} \quad$ Retail's Order quantity

$\mathrm{Q}_{\text {s }}$ Manufacturer's production quantity

$\mathrm{Q}_{\max }$ Retailer's maximum inventory Level

\section{COORDINATION MODEL}

\subsection{Retailers Inventory Model}

In this section we develop the coordination model of the two echelon supply chain based on price discounts. For obtaining the coordination model, we first derive the retailers profit in a replenishment cycle utilizing the retailer's inventory model. In the retailers inventory model we assume that there is an initial replenishment and the inventory level reaches max. Level at $\mathrm{t}=0$.

During the period 0 to $t_{1}$ the inventory decreases due to deterioration and demand and reaches to zero at time $\mathrm{t}=\mathrm{t}_{1}$.
During the period $t_{1}$ to $T$ there is a '-ve' inventory due to shortages since shortages are allowed and fully back logged. The schematic diagram representing the Inventory level $\mathrm{I}(\mathrm{t})$ is shown in figure 1 .

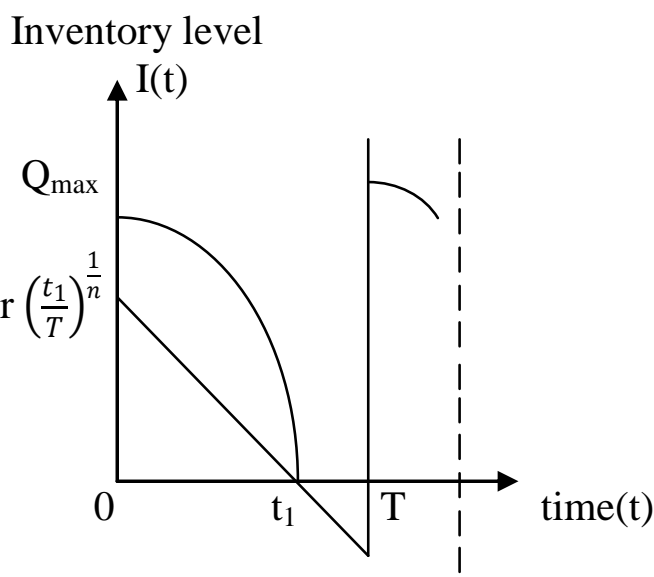

Fig.1 The retailer's inventory level

With these considerations the differential equations governing the inventory level at time $t$ are.

$$
\frac{d I(t)}{d t}=-\theta I(t)-\frac{r t^{\frac{1}{n}-1}}{n T^{\frac{1}{n}}} \text { for } t \epsilon\left[0, t_{1}\right]
$$

(1)

$$
\frac{d I(t)}{d t}=-\frac{r t^{\frac{1}{n}-1}}{n T^{\frac{1}{n}}} \text { for } t \epsilon\left[t_{1}, T\right]
$$

With the boundary condition $\mathrm{I}\left(\mathrm{t}_{1}\right)=0$ solving the differential equations(1) and (2),

We get

$$
\begin{aligned}
I(t)=\frac{r}{e^{\theta t} T^{1 / n}}\left[\left(t_{1}^{\frac{1}{n}}-t^{\frac{1}{n}}\right)\right. & \\
& \left.+\frac{\theta}{n+1}\left(t_{1}^{\frac{1}{n}+1}-t^{\frac{1}{n}+1}\right)\right], t \in\left[0, t_{1}\right]
\end{aligned}
$$

$$
I(t)=-\frac{r}{T^{\frac{1}{n}}}\left[t^{\frac{1}{n}}-t_{1}^{\frac{1}{n}}\right], t \in\left[t_{1}, T\right]
$$

(4)

From figure $1 . \mathrm{Q}_{\max }=\mathrm{I}(0)$, the maximum inventory level is

$$
Q_{\text {max }}=I(t)_{t=0}=\frac{r}{T^{\frac{1}{n}}}\left[t_{1}^{\frac{1}{n}}+\frac{\theta}{n+1}\left(t_{1}^{\frac{1}{n}+1}\right)\right]
$$

The shortage quantity at interval $\left[\mathrm{t}_{1}, \mathrm{~T}\right]$ is

$$
S=\frac{r}{T^{\frac{1}{n}}}\left[T^{\frac{1}{n}}-t_{1}^{\frac{1}{n}}\right]
$$

From Equations(5) and (6) we have the order quantity in the replenishment cycle as

$Q_{r}=Q_{\max }+S=\frac{r}{T^{\frac{1}{n}}}\left[\frac{\theta}{n+1}\left(t_{1}^{\frac{1}{n}+1}\right)+T^{\frac{1}{n}}\right]$ 
The total cost for the retail during the replenishment cycle consists of the ordering cost $\left(\mathrm{C}_{\mathrm{o}}\right)$, the backlog cost $\left(\mathrm{C}_{\mathrm{s}}\right)$, the holding cost $\left(\mathrm{C}_{\mathrm{h}}\right)$, the purchase cost $(\mathrm{CP})$ and the disposal cost $\left(\mathrm{C}_{\mathrm{d}}\right)$. The retails revenue is denoted by $\mathrm{C}_{\mathrm{g}}$.

1. There is an initial replenishment at the start of the cycle then the ordering cost is

$\mathrm{C}_{\mathrm{o}}=\mathrm{C}_{\mathrm{ro}}$

2. The backlog cost during the replenishment cycle is

$$
\begin{aligned}
C_{S} & =C_{r l} \int_{t_{1}}^{T} I(t) d t \\
& =\frac{C_{r l} r}{T^{\frac{1}{n}}}\left[\frac{n}{n+1}\left(T^{\frac{1}{n}+1}-t_{1}^{\frac{1}{n}+1}\right)+t_{1}^{\frac{1}{n}}\left(t_{1}-T\right)\right]
\end{aligned}
$$

3. From fig 1 inventory occurs at interval[ $\left.0, t_{1}\right]$. The holding cost is

$$
\begin{aligned}
\mathrm{C}_{\mathrm{h}} & =\mathrm{h}_{\mathrm{r}} \int_{0}^{\mathrm{t}_{1}} \mathrm{I}(\mathrm{t}) \mathrm{dt} \\
& =\frac{h_{r} r}{T^{\frac{1}{n}}}\left[\frac{t_{1}^{\frac{1}{n}+1}}{n+1}+\frac{\theta}{2(2 n+1)} t_{1}^{\frac{1}{n}+2}\right]
\end{aligned}
$$

4. The purchase cost during the replenishment cycle is

$$
\begin{aligned}
\mathrm{C}_{\mathrm{p}} & =\mathrm{A}\left(\mathrm{Q}_{\max }+\mathrm{S}\right) \\
& =\frac{A r}{T^{\frac{1}{n}}}\left[\frac{\theta}{n+1} t_{1}^{\frac{1}{n}+1}+T^{\frac{1}{n}}\right]
\end{aligned}
$$

5. The disposal cost for deteriorating units

is

$$
\begin{aligned}
C_{d} & =C_{r d}\left(Q_{\max }-\int_{0}^{t_{1}} \frac{r t^{\frac{1}{n}-1}}{n T^{\frac{1}{n}}} d t\right) \\
& =\frac{C_{r d} r}{T^{\frac{1}{n}}}\left[\frac{\theta}{n+1} t_{1}^{\frac{1}{n}+1}\right]
\end{aligned}
$$

6. The retails revenue is

$$
C_{g}=B \int_{0}^{T r} \frac{t^{\frac{1}{n}-1}}{n T^{\frac{1}{n}}} d t=B r
$$

So, the retailers profit in a replenishment cycle is

$$
\begin{aligned}
& \mathrm{TCR}=\mathrm{C}_{\mathrm{g}}-\left(\mathrm{C}_{\mathrm{o}}+\mathrm{C}_{\mathrm{s}}+\mathrm{C}_{\mathrm{h}}+\mathrm{C}_{\mathrm{p}}+\mathrm{C}_{\mathrm{d}}\right) \\
& T C R=B r-\left[C_{r o}+\frac{C_{r 1} r}{T^{\frac{1}{n}}}\left\{\frac{n}{n+1}\left(T^{\frac{1}{n}+1}-t_{1}^{\frac{1}{n}+1}\right)+\right.\right. \\
& \left.\left.t_{1}^{\frac{1}{n}}\left(t_{1}-T\right)\right\}+\frac{h_{r} r}{T^{\frac{1}{n}}} \frac{t_{1}^{\frac{1}{n}+1}}{n+1}+\frac{\theta}{2(2 n+1)} t_{1}^{\frac{1}{n}+2}\right\}+\frac{A r}{T^{\frac{1}{n}}}\left\{\frac{\theta}{n+1} t_{1}^{\frac{1}{n}+1}+\right. \\
& \left.\left.T^{\frac{1}{n}}\right\}+\frac{C_{r d} r}{T^{\frac{1}{n}}}\left\{\frac{\theta}{n+1} t_{1}^{\frac{1}{n}+1}\right\}\right]
\end{aligned}
$$

The necessary conditions for optimality

$$
\begin{aligned}
& \frac{\partial(T C R)}{\partial t_{1}}=0, \frac{\partial(T C R)}{\partial T}=0 \\
& \frac{\partial(T C R)}{\partial t_{1}}= \\
& C_{r l}\left[1-\frac{T}{t_{1}}\right]+h_{r}\left[1+\frac{\theta}{2} t_{1}\right]+\theta\left(A+C_{r d}\right)=0
\end{aligned}
$$

$$
\begin{aligned}
& \frac{\partial(T C R)}{\partial T}=C_{r l} r\left\{\frac{-n^{2}}{(n+1)} T^{\frac{1}{n}+1}+\frac{1}{n+1} t_{1}^{\frac{1}{n}+1}+t_{1}^{\frac{1}{n}}(n-1) T\right\}+ \\
& h_{r}\left(\frac{t_{1}^{\frac{1}{n}+1}}{n+1}+\frac{\theta}{2(2 n+1)} t_{1}^{\frac{1}{n}+2}\right)+\left(A+C_{r d}\right) \frac{\theta}{n+1} t_{1}^{\frac{1}{n}+1}=0
\end{aligned}
$$

By solving simultaneous equations (15) and (16) we get $t_{1}$ and $\mathrm{T}$.

The retailers economic order quantity for maximum profit is

$Q_{r}^{1}=\frac{r}{T^{\frac{1}{n}}}\left[\frac{\theta}{n+1}\left(t_{1}^{\frac{1}{n}+1}\right)+T^{\frac{1}{n}}\right]$

Hence the retailer's maximum profit is

$$
\begin{aligned}
& T C R^{*}=n^{1}\left\{B r-\left[C_{r o}+\frac{C_{r l}}{T^{1 \frac{1}{n}}}\left\{\frac{n}{n+1}\left(T^{\frac{1}{n}+1}-t_{1}^{\frac{1}{n}+1}\right)+\right.\right.\right. \\
& \left.t_{1}^{\frac{1}{n}}\left(t_{1}-T\right)\right\}+\frac{h_{r} r}{T^{\frac{1}{n}}}\left\{\frac{t_{1}^{\frac{1}{n}+1}}{n+1}+\frac{\theta}{2(2 n+1)} t_{1}^{\frac{1}{n}+2}\right\}+\frac{A r}{T^{\frac{1}{n}}}\left\{\frac{\theta}{n+1} t_{1}^{\frac{1}{n}+1}+\right. \\
& \left.\left.\left.T^{\frac{1}{n}}\right\}+\frac{C_{r d} r}{T^{\frac{1}{n}}}\left\{\frac{\theta}{n+1} t_{1}^{\frac{1}{n}+1}\right\}\right]\right\}
\end{aligned}
$$

\subsection{Manufacturer's Inventory Model}

The manufacturer's inventory model is developed based on retailer's orders. Assuming that there is no deterioration at manufacturer's inventory level. The manufacturer's optimum profit is derived through the setup cost, holding cost and production cost.

The production lot-size per cycle is

$T_{s}=\frac{T Q_{s}}{n^{1} Q_{r}}$

Production time during period $\mathrm{T}_{\mathrm{S}}$ is

$t_{s}=\frac{Q_{s}}{P_{s}}$

Ordering times is

$n_{s}=\frac{n^{1} Q_{r}}{Q_{s}}$

Average inventory level is

$\frac{t_{s}}{2 T_{s}} Q_{s}=\frac{n^{1} Q_{r} Q_{s}}{2 P_{s}}$

Hence the manufacture's optimum profit is

$T C M=\left(A-C_{m}\right) n^{1} Q_{r}-h_{s} \frac{n^{1} Q_{r} Q_{s}}{2 T P_{s}}-C_{s} \frac{n^{1} Q_{r}}{Q_{s}}$

Let

$\frac{d(T C M)}{d Q_{s}}=0$, we have the production lot-size for Maximum Avenue

$$
Q_{s}^{1}=\sqrt{\frac{2 T C_{s} P_{s}}{h_{s}}}
$$

So the optimum order times is

$n_{s}=\frac{n^{1} Q_{r}}{Q_{s}^{1}}=n^{1} Q_{r} \sqrt{\frac{h s}{2 T C s P s}}$

Then the manufacture's maximum profit is

$T C M^{*}=n^{1} Q_{r}\left[\left(A-c_{m}\right)-\sqrt{\frac{2 C_{s} h_{s}}{T P_{s}}}\right]$

With the retailers inventory model and the manufacturers inventory models discussed in sections 3.1 and 3.2, we have the total revenue of the supply chain under decentralized decision is 


$$
\begin{aligned}
& \emptyset_{1}=\mathrm{TCR}^{*}+\mathrm{TCM}^{*}=n^{1}\left\{B r-\left[C_{r o}+\frac{C_{r l}}{T^{\frac{1}{n}}}\left\{\frac{n}{n+1}\left(T^{\frac{1}{n}+1}-t_{1}^{\frac{1}{n}+1}\right)+\right.\right.\right. \\
& \left.t_{1}^{\frac{1}{n}}\left(t_{1}-T\right)\right\}+\frac{h_{r} r}{T^{\frac{1}{n}}}\left\{\frac{t_{1}^{\frac{1}{n}+1}}{n+1}+\frac{\theta}{2(2 n+1)} t_{1}^{\frac{1}{n}+2}\right\}+\frac{A r}{T^{\frac{1}{n}}}\left\{\frac{\theta}{n+1} t_{1}^{\frac{1}{n}+1}+T^{\frac{1}{n}}\right\}+ \\
& \left.\left.\frac{C_{r d} r}{T^{\frac{1}{n}}}\left\{\frac{\theta}{n+1} t_{1}^{\frac{1}{n}+1}\right\}\right]\right\}+n^{1} Q_{r}
\end{aligned}
$$

\subsection{Lot sizing Coordination Model Based on Price Discount}

In the equation (23) it is observed that this maximum revenue of the supply chain does not satisfy both retailer and manufactures, since there is no coordination between the two and both TCR and TCM are optimized separately.

But

$Q_{s}^{1} \neq n^{1} Q_{r}^{1}$ in general as a result of it the manufacturers cost will greater and profit will less than that of the optimum lot size point due to order production mode. But in price discount strategy of the supply chain the coordination between the manufacturer and the retailer is done when the manufacturer stimulate the retailers to order more close to the $Q_{s}^{1}$ derived in production inventory model by offering price discounts. In this paper we propose to utilize the

$P=A-k \frac{Q_{r}-Q_{r}^{1}}{Q_{s}^{1}-n^{1} Q_{r}^{1}}, k>0$

This model considers both quantity increased discount and quantity decreased one, and reduce the retailer's benefit when the retailer makes a false report of $Q_{r}^{1}$ on the condition of information dissymmetry.

Further, at the same time the manufacture obtains the optimum profit, it is necessary to make retailers cooperate with pleasure that the retailer's profit should not less than that of noncooperation condition, and the retailers cost does not increase.

The coordination objective here is to maximize the total profit of supply chain, by determining the discount coefficient $\mathrm{k}$, order lotsize $\mathrm{Q}_{\mathrm{r}}$ and production lot-size $\mathrm{Q}_{\mathrm{s}}$. Equation, (7) indicates that the value of $Q_{r}$ is a function of variable $t_{1}$, and Eqn. (20) is a function of variable $\mathrm{T}$. Hence the mathematical model for inventory-production system is presented below.

$$
\begin{gathered}
\emptyset_{2}=\max \left\{n^{1} B r-n^{1}\left[C_{r 0}+\frac{C_{r l} r}{T^{\frac{1}{n}}}\left\{\frac{n}{n+1}\left(T^{\frac{1}{n}+1}-t_{1}^{\frac{1}{n}+1}\right)+\right.\right.\right. \\
\left.t_{1}^{\frac{1}{n}}\left(t_{1}-T\right)\right\}+\frac{h_{r} r}{T^{\frac{1}{n}}}\left\{\frac{t_{1}^{\frac{1}{n}+1}}{n+1}+\frac{\theta}{2(2 n+1)} t_{1}^{\frac{1}{n}+2}\right\}+\frac{P r}{T^{\frac{1}{n}}}\left\{\frac{\theta}{n+1} t_{1}^{\frac{1}{n}+1}+\right. \\
\left.\left.T^{\frac{1}{n}}\right\}+\frac{C_{r d} r}{T^{\frac{1}{n}}}\left\{\frac{\theta}{n+1} t_{1}^{\frac{1}{n}+1}\right\}\right]+n^{1} Q_{r}\left[\left(P-C_{m}\right)-\sqrt{\left.\left.\frac{2 C_{s} h_{s}}{T P_{s}}\right]\right\}}\right) \\
B r-\left[C_{r 0}+\frac{C_{r l} r}{T^{\frac{1}{n}}}\left\{\frac{n}{n+1}\left(T^{\frac{1}{n}+1}-t_{1}^{\frac{1}{n}+1}\right)+t_{1}^{\frac{1}{n}}\left(t_{1}-T\right)\right\}+\right. \\
\frac{h_{r} r}{T^{\frac{1}{n}}}\left\{\frac{t_{1}^{\frac{1}{n}+1}}{n+1}+\frac{\theta}{2(2 n+1)} t_{1}^{\frac{1}{n}+2}\right\}+\frac{P r}{T^{\frac{1}{n}}}\left\{\frac{\theta}{n+1} t_{1}^{\frac{1}{n}+1}+T^{\frac{1}{n}}\right\}+ \\
\left.\frac{C_{r d} r}{T^{\frac{1}{n}}}\left\{\frac{\theta}{n+1} t_{1}^{\frac{1}{n}+1}\right\}\right] \geq T C R^{*} \quad(26) \\
{\left[\left(P-C_{m}\right) n^{1} Q_{r}-h_{s} \frac{n^{1} Q_{r} Q_{s}}{2 T P_{s}}-C_{s} \frac{n^{1} Q_{r}}{Q_{s}}\right] \geq T C M^{*}} \\
P=A-k \frac{Q_{r}-Q_{r}^{1}}{Q_{s}^{1}-n^{1} Q_{r}^{1}}, k>0
\end{gathered}
$$

$C_{m} \leq P \leq A$

$$
\begin{aligned}
& Q_{S}^{1}-n^{1} * Q_{r}>0 \\
& Q_{r}=\frac{r}{T^{\frac{1}{n}}}\left[\frac{\theta}{n+1}\left(t_{1}^{\frac{1}{n}+1}\right)+T^{\frac{1}{n}}\right] \\
& 0 \leq t_{1} \leq T \\
& Q_{S}^{1}=\sqrt{\frac{2 T C_{s} P_{s}}{h_{s}}} \\
& Q_{r}^{1}=\frac{r}{T^{1 \frac{1}{n}}}\left[\frac{\theta}{n+1}\left(t_{1}^{\frac{1}{n}+1}\right)+T^{\frac{1}{n}}\right]
\end{aligned}
$$

The objective function seeks to maximize total profit. Constraints (26) and (27) ensure the Pareto improvement for both cooperation sides. Constraints (26) and (27) guarantee the rationality of price constraint (30) implies that the manufacture will not be out of stock.

Restrictions (31-34) are from the previous section.

\section{NUMERICAL ILLUSTRATION}

To illustrate the developed model, we consider a system with one manufacture and three retailers, i.e. $n^{1}=3$.

The relevant parameter values are shown in Table 1.

TABLE.1

The Relevant Parameter Values

\begin{tabular}{|l|c|l|l|l|l|l|}
\hline Parameter & $\mathrm{R}$ & $\theta$ & $\mathrm{C}_{\mathrm{rl}}$ & $\mathrm{h}_{\mathrm{r}}$ & $\mathrm{C}_{\mathrm{ro}}$ & $\mathrm{C}_{\mathrm{rd}}$ \\
\hline Value & 20 & 0.02 & 1 & 1 & 20 & 0.5 \\
\hline Parameter & $\mathrm{A}$ & $\mathrm{B}$ & $\mathrm{C}_{\mathrm{m}}$ & $\mathrm{h}_{\mathrm{s}}$ & $\mathrm{C}_{\mathrm{s}}$ & $\mathrm{P}_{\mathrm{s}}$ \\
\hline Value & 10 & 12 & 3 & 0.4 & 10 & 200 \\
\hline
\end{tabular}

The optimal solution of the system is presented below.

1) On condition of decentralized decision, the retailers actual order quantity is the economic order quantity $Q_{r}^{1}=6.7401$, and the corresponding maximum profit $\mathrm{TCR}=17.2936$. The corresponding manufactures production lot-size $Q_{s}^{1}=60.1087$, and the maximum profit $\mathrm{TCM}=134.8146 .2$ ) with coordination method, we obtain $\mathrm{t}_{1}=0.4042, \mathrm{k}=0.18, \mathrm{~T}=0.8945 . Q_{r}^{1}=20.0362$, and the retailers maximum profit $\mathrm{TCR}=51.8810$. The corresponding manufactures production lot-size $Q_{s}^{1}=94.5801$, and the manufactures maximum profit $\mathrm{TCM}=404.4437$. Table 2 shows the Optimal values of $\mathrm{Q}_{\mathrm{r}}, \mathrm{Q}_{\mathrm{s}}$ based on different types of models.

TABLE. 2

Values of $\mathrm{Q}_{\mathrm{r}}$ and $\mathrm{Q}_{\mathrm{s}}$

\begin{tabular}{|l|l|l|l|}
\hline & $\mathrm{Q}_{\mathrm{r}}$ & $\mathrm{n}^{1} \mathrm{Q}_{\mathrm{r}}$ & $\mathrm{Q}_{\mathrm{S}}$ \\
\hline $\begin{array}{l}\text { Non- } \\
\text { coordination }\end{array}$ & 6.7401 & 36.735 & 60.1087 \\
\hline Coordination & 20.0362 & 60.060 & 94.5801 \\
\hline & $\mathrm{TCR}$ & $\mathrm{TCM}$ & $\emptyset$ \\
\hline $\begin{array}{l}\text { Non- } \\
\text { coordination }\end{array}$ & 17.2936 & 134.8146 & 152.1083 \\
\hline \begin{tabular}{l} 
Coordination \\
\hline
\end{tabular} & 51.8810 & 404.4437 & 456.3248 \\
\hline
\end{tabular}


From Table 2 It is observed that, based on decentralized decision $Q_{s}^{1}-n^{1} Q_{r}^{1}>0$, the manufacture adopts quantity increased discount policy. Both the retailers and the manufactures profit increased. Therefore, from the economical point of view, the coordination mechanism is effective.

\section{SENSITIVITY ANALYSIS}

The sensitivity analysis on the effects of changes in the model parameters such as the rate of deterioration, retailers inventory holding cost, manufacturer's inventory holding cost, manufacturer's setup cost, retailers backlog cost, retailers disposal cost for deteriorating items, retailers ordering cost, manufacturer's production rate, by changing each of the parameter by $-15 \%,-10 \%,-$ $5 \%, 0 \%,+5 \%,+10 \%,+15 \%$ and keeping the other parameters unchanged is carried for the model under consideration. The results are presented in tables 3 and 4 . The following observations are made from tables 3 and 4 .

1. It is observed that as the deterioration rate increases the net profit is decreasing when other parameters remains fixed in both coordination and non coordination models whereas this decrease in coordination model is less compared to that of non coordination model. This is because there is cooperation between retailer and supplier.

Table 3. Sensitivity analysis of non-coordination model
2. Similarly regarding the holding costs of retailers and producers the profit for both the models is decreasing when the costs are increasing. This decrease in profit is small in coordination model compared to that of non coordination model.

3. With respect to the increase in other costs like manufacturers set up cost (Cs), disposal cost for deteriorating items $\left(\mathrm{C}_{\mathrm{rd}}\right)$, the profits in both the models are decreasing when other parameters remain fixed. This rate of decrease in profit for coordination model is small compared to that of non coordination model.

4. With respect to increase in the retailers backlog cost $\left(\mathrm{C}_{\mathrm{r}}\right)$ the profit for both the models is increasing, when retailers ordering costs $\left(\mathrm{C}_{\mathrm{ro}}\right)$ increases profit for both the models is not effected and when production rate (Ps) increases the profits for both the models are increasing.

With the sensitivity analysis one can understand that the supply chain profit and optimal ordering quantities of the manufacturer and retailers are tremendously influenced by deteriorating parameter and costs. This model is much useful for scheduling the supply chain of several products in industries dealing with deteriorated items. This model can also be extended for different types of demand at retailers and manufacturer levels which require further investigations.

\begin{tabular}{|c|c|c|c|c|c|c|c|c|}
\hline \multirow{2}{*}{$\begin{array}{l}\text { Variation } \\
\text { in } \\
\text { parameters }\end{array}$} & \multirow{2}{*}{$\begin{array}{l}\text { Optimal } \\
\text { Policies }\end{array}$} & \multicolumn{7}{|c|}{ Change in Parameters } \\
\hline & & $-15 \%$ & $-10 \%$ & $-5 \%$ & 0\% & $+5 \%$ & $+10 \%$ & $+15 \%$ \\
\hline \multirow[t]{5}{*}{1} & $\mathrm{Q}_{\mathrm{r}}$ & 6.7399 & 6.7401 & 6.7401 & 6.7401 & 6.7401 & 6.7402 & 6.7402 \\
\hline & $Q_{s}$ & 60.0955 & 60.1001 & 60.1044 & 60.1087 & 60.1128 & 60.1209 & 60.1209 \\
\hline & $T C R$ & 17.3067 & 17.2022 & 17.2978 & 17.2936 & 17.2896 & 17.2820 & 17.2820 \\
\hline & $T C M$ & 134.8095 & 134.8114 & 134.8131 & 134.8146 & 134.8158 & 134.8178 & 134.8178 \\
\hline & $\varnothing$ & 152.1162 & 152.0136 & 152.1109 & 152.1083 & 152.1054 & 152.0998 & 152.0998 \\
\hline \multirow{5}{*}{$h_{r}$} & $\mathrm{Q}_{\mathrm{r}}$ & 6.7476 & 6.7451 & 6.7426 & 6.7401 & 6.7376 & 6.7351 & 6.7325 \\
\hline & $Q_{s}$ & 60.1252 & 60.1197 & 60.1142 & 60.1087 & 60.1032 & 60.0981 & 60.0930 \\
\hline & $T C R$ & 17.3461 & 17.3286 & 17.3111 & 17.2936 & 17.2761 & 17.2617 & 17.2473 \\
\hline & $T C M$ & 134.9670 & 134.9162 & 134.8654 & 134.8146 & 134.7638 & 134.7144 & 134.6650 \\
\hline & $\emptyset$ & 152.3131 & 152.2448 & 152.1765 & 152.1083 & 152.0399 & 151.9761 & 151.9123 \\
\hline \multirow{5}{*}{$h_{s}$} & $\mathrm{Q}_{\mathrm{r}}$ & 6.7480 & 6.7454 & 6.7427 & 6.7401 & 6.7376 & 6.7351 & 6.7328 \\
\hline & $Q_{s}$ & 60.1009 & 60.1035 & 60.1061 & 60.1087 & 60.1111 & 60.1136 & 60.1160 \\
\hline & $T C R$ & 17.5745 & 17.4801 & 17.3857 & 17.2936 & 17.2037 & 17.1157 & 17.0296 \\
\hline & $T C M$ & 134.9754 & 134.9210 & 134.8666 & 134.8146 & 134.7646 & 134.7166 & 134.6703 \\
\hline & $\varnothing$ & 152.5499 & 152.4011 & 152.2523 & 152.1083 & 151.9683 & 151.8323 & 151.6999 \\
\hline \multirow{5}{*}{$C_{s}$} & $\mathrm{Q}_{\mathrm{r}}$ & 6.7125 & 6.7217 & 6.7309 & 6.7401 & 6.7493 & 6.7580 & 6.7672 \\
\hline & $Q_{s}$ & 60.1150 & 60.1129 & 60.1108 & 60.1087 & 60.1066 & 60.1040 & 60.1019 \\
\hline & TCR & 17.0656 & 17.1416 & 17.2176 & 17.2936 & 17.3696 & 17.4627 & 17.5387 \\
\hline & $T C M$ & 135.2787 & 135.1240 & 134.9693 & 134.8146 & 134.6599 & 134.4980 & 134.3433 \\
\hline & $\varnothing$ & 152.3443 & 152.2656 & 152.1869 & 152.1083 & 152.0295 & 151.9608 & 151.8820 \\
\hline \multirow{5}{*}{$C_{r l}$} & $\mathrm{Q}_{\mathrm{r}}$ & 6.7402 & 6.7402 & 6.7401 & 6.7401 & 6.7400 & 6.7399 & 6.7398 \\
\hline & $Q_{s}$ & 60.0974 & 60.1010 & 60.1046 & 60.1087 & 60.1123 & 60.1162 & 60.1198 \\
\hline & $T C R$ & 17.4766 & 17.4202 & 17.3638 & 17.2936 & 17.2372 & 17.1679 & 17.1115 \\
\hline & $T C M$ & 134.8185 & 134.8169 & 134.8153 & 134.8146 & 134.8139 & 134.8123 & 134.8107 \\
\hline & $\varnothing$ & 152.2951 & 152.2371 & 152.1792 & 152.1083 & 152.0511 & 151.9802 & 151.9223 \\
\hline \multirow{4}{*}{$C_{r d}$} & $\mathrm{Q}_{\mathrm{r}}$ & 6.7401 & 6.7401 & 6.7401 & 6.7401 & 6.7400 & 6.7400 & 6.7400 \\
\hline & $Q_{s}$ & 60.1088 & 60.1088 & 60.1087 & 60.1087 & 60.1086 & 60.1085 & 60.1085 \\
\hline & $T C R$ & 17.2942 & 17.2940 & 17.2938 & 17.2936 & 17.2934 & 17.2932 & 17.2930 \\
\hline & $T C M$ & 134.8161 & 134.8156 & 134.8151 & 134.8146 & 134.8141 & 134.8136 & 134.8130 \\
\hline
\end{tabular}




\begin{tabular}{|l|l|l|l|l|l|l|l|l|}
\multicolumn{1}{|c|}{} & $\emptyset$ & 152.1103 & 152.1096 & 152.1089 & 152.1083 & 152.1075 & 152.1068 & 152.1060 \\
\hline \multirow{5}{*}{$C_{r o}$} & $\mathrm{Q}_{\mathrm{r}}$ & 6.7500 & 6.7466 & 6.7432 & 6.7401 & 6.7367 & 6.7333 & 6.7299 \\
\cline { 2 - 9 } & $Q_{s}$ & 60.1178 & 60.1147 & 60.1116 & 60.1087 & 60.1056 & 60.1025 & 60.0994 \\
\cline { 2 - 9 } & $T C R$ & 19.9692 & 19.0781 & 18.1870 & 17.2936 & 16.4025 & 15.5114 & 14.6203 \\
\cline { 2 - 9 } & $T C M$ & 135.0118 & 134.9448 & 134.8778 & 134.8146 & 134.7476 & 134.6806 & 134.6136 \\
\cline { 2 - 9 } & $\varnothing$ & 154.9810 & 154.0229 & 153.0649 & 152.1083 & 151.1501 & 150.1920 & 149.2339 \\
\hline \multirow{5}{*}{$P_{s}$} & $\mathrm{Q}_{\mathrm{r}}$ & 6.7316 & 6.7343 & 6.7374 & 6.7401 & 6.7426 & 6.7449 & 6.7471 \\
\cline { 2 - 9 } & $Q_{s}$ & 60.1172 & 60.1146 & 60.1113 & 60.1087 & 60.1062 & 60.1040 & 60.1019 \\
\cline { 2 - 9 } & $T C R$ & 16.9848 & 17.0794 & 17.1990 & 17.2936 & 17.3813 & 17.4627 & 17.5387 \\
\cline { 2 - 9 } & $T C M$ & 134.6465 & 134.6981 & 134.7620 & 134.8146 & 134.8641 & 134.9110 & 134.9554 \\
\cline { 2 - 9 } & $\varnothing$ & 151.6313 & 151.7775 & 151.9610 & 152.1083 & 152.2454 & 152.3737 & 152.4941 \\
\hline
\end{tabular}

Table 4. Sensitivity analysis of co-ordination model

\begin{tabular}{|c|c|c|c|c|c|c|c|c|}
\hline \multirow{2}{*}{$\begin{array}{l}\text { Variation } \\
\text { in } \\
\text { parameters }\end{array}$} & \multirow{2}{*}{$\begin{array}{l}\text { Optimal } \\
\text { Policies }\end{array}$} & \multicolumn{7}{|c|}{ Change in Parameters } \\
\hline & & $-15 \%$ & $-10 \%$ & $-5 \%$ & $0 \%$ & $+5 \%$ & $+10 \%$ & $+15 \%$ \\
\hline \multirow{5}{*}{$\theta$} & $\mathrm{Q}_{\mathrm{r}}$ & 20.0318 & 20.0333 & 20.0348 & 20.0362 & 20.0376 & 20.0389 & 20.0403 \\
\hline & $Q_{s}$ & 95.1300 & 94.9456 & 94.7623 & 94.5801 & 94.3991 & 94.2193 & 94.0406 \\
\hline & $T C R$ & 51.9203 & 51.9067 & 51.8936 & 51.8810 & 51.8689 & 51.8572 & 51.8461 \\
\hline & $T C M$ & 404.4286 & 404.4343 & 404.4393 & 404.4437 & 404.4475 & 404.4507 & 404.4533 \\
\hline & $\varnothing$ & 456.3489 & 456.3410 & 456.3329 & 456.3248 & 456.3164 & 456.3079 & 456.2994 \\
\hline \multirow{5}{*}{$h_{r}$} & $\mathrm{Q}_{\mathrm{r}}$ & 20.0410 & 20.0396 & 20.0379 & 20.0362 & 20.0344 & 20.0327 & 20.0310 \\
\hline & $Q_{s}$ & 97.1361 & 96.2841 & 95.4321 & 94.5801 & 93.7281 & 92.9016 & 92.0496 \\
\hline & $T C R$ & 52.0391 & 51.9864 & 51.9337 & 51.8810 & 51.8283 & 51.7853 & 51.7326 \\
\hline & $T C M$ & 404.9006 & 404.7483 & 404.5960 & 404.4437 & 404.2914 & 404.1431 & 403.9908 \\
\hline & $\varnothing$ & 456.9397 & 456.7347 & 456.5297 & 456.3248 & 456.1198 & 455.9284 & 455.7234 \\
\hline \multirow{5}{*}{$h_{s}$} & $\mathrm{Q}_{\mathrm{r}}$ & 20.0336 & 20.0345 & 20.0353 & 20.0362 & 20.0370 & 20.0378 & 20.0386 \\
\hline & $Q_{s}$ & 98.5986 & 97.2907 & 95.8880 & 94.5801 & 93.3561 & 92.2068 & 91.1245 \\
\hline & $T C R$ & 52.7165 & 52.4403 & 52.1572 & 51.8810 & 51.6111 & 51.3473 & 51.0890 \\
\hline & $T C M$ & 404.9193 & 404.7631 & 404.5999 & 404.4437 & 404.2939 & 404.1497 & 404.0109 \\
\hline & $\varnothing$ & 457.6358 & 457.2034 & 456.7571 & 456.3248 & 455.9050 & 455.4970 & 455.0999 \\
\hline \multirow{5}{*}{$C_{s}$} & $\mathrm{Q}_{\mathrm{r}}$ & 20.0385 & 20.0378 & 20.0370 & 20.0362 & 20.0353 & 20.0346 & 20.0339 \\
\hline & $Q_{s}$ & 91.0752 & 92.2435 & 93.4118 & 94.5801 & 95.8597 & 97.0280 & 98.1963 \\
\hline & $T C R$ & 51.1973 & 51.4252 & 51.6531 & 51.8810 & 52.1604 & 52.3883 & 52.6162 \\
\hline & $T C M$ & 405.8360 & 405.3719 & 404.9078 & 404.4437 & 403.9581 & 403.4940 & 403.0299 \\
\hline & $\varnothing$ & 457.0333 & 456.7971 & 456.5609 & 456.3248 & 456.1185 & 455.8823 & 455.6461 \\
\hline \multirow{5}{*}{$C_{r l}$} & $\mathrm{Q}_{\mathrm{r}}$ & 20.0324 & 20.0336 & 20.0348 & 20.0362 & 20.0375 & 20.0387 & 20.0399 \\
\hline & $Q_{s}$ & 95.2196 & 95.0093 & 94.7990 & 94.5801 & 94.3610 & 94.1507 & 93.9404 \\
\hline & $T C R$ & 52.4298 & 52.2607 & 52.0916 & 51.8810 & 51.6729 & 51.5038 & 51.3347 \\
\hline & $T C M$ & 404.4553 & 404.4506 & 404.4459 & 404.4437 & 404.4415 & 404.4368 & 404.4321 \\
\hline & $\varnothing$ & 456.8851 & 456.7113 & 456.5375 & 456.3248 & 456.1144 & 455.9406 & 455.7669 \\
\hline \multirow{5}{*}{$C_{r d}$} & $\mathrm{Q}_{\mathrm{r}}$ & 20.0362 & 20.0362 & 20.0362 & 20.0362 & 20.0362 & 20.0362 & 20.0361 \\
\hline & $Q_{s}$ & 94.6059 & 94.5973 & 94.5887 & 94.5801 & 94.5715 & 94.5629 & 94.5543 \\
\hline & $T C R$ & 51.8827 & 51.8821 & 51.8816 & 51.8810 & 51.8804 & 51.8798 & 51.8792 \\
\hline & $T C M$ & 404.4484 & 404.4468 & 404.4453 & 404.4437 & 404.4422 & 404.4407 & 404.4391 \\
\hline & $\varnothing$ & 456.3311 & 456.3289 & 456.3269 & 456.3248 & 456.3226 & 456.3205 & 456.3183 \\
\hline \multirow{5}{*}{$C_{r o}$} & $\mathrm{Q}_{\mathrm{r}}$ & 20.0392 & 20.0382 & 20.0372 & 20.0362 & 20.0352 & 20.0342 & 20.0332 \\
\hline & $Q_{s}$ & 98.4219 & 97.1413 & 95.8607 & 94.5801 & 93.2542 & 91.9283 & 90.6024 \\
\hline & $T C R$ & 59.9079 & 57.2345 & 54.5611 & 51.8810 & 49.2076 & 46.5342 & 43.8608 \\
\hline & $T C M$ & 405.0128 & 404.8231 & 404.6334 & 404.4437 & 404.2427 & 404.0530 & 403.8633 \\
\hline & $\varnothing$ & 464.9207 & 462.0576 & 459.1945 & 456.3248 & 453.4504 & 450.5872 & 447.7241 \\
\hline \multirow{5}{*}{$P_{s}$} & $\mathrm{Q}_{\mathrm{r}}$ & 20.0390 & 20.0380 & 20.0371 & 20.0362 & 20.0354 & 20.0346 & 20.0339 \\
\hline & $Q_{s}$ & 90.5764 & 91.8627 & 93.2938 & 94.5801 & 95.8237 & 97.0280 & 98.1963 \\
\hline & $T C R$ & 50.9544 & 51.2383 & 51.5971 & 51.8810 & 52.1439 & 52.3883 & 52.6162 \\
\hline & $T C M$ & 403.9394 & 404.0970 & 404.2861 & 404.4437 & 404.5924 & 404.7329 & 404.8661 \\
\hline & $\varnothing$ & 454.8938 & 455.3353 & 455.8832 & 456.3248 & 456.7363 & 457.1212 & 457.4823 \\
\hline
\end{tabular}




\section{CONCLUSION}

Two-echelon supply chain scheduling is an important consideration for both manufacturer and retailers. In this paper a coordination model for a two echelon supply chain with price discounts is developed and analyzed under the coordination between manufacturers and retailers. It is also assumed that the item under consideration is subject to deterioration. By using the differential equations the instantaneous state of inventory at retailer's level is derived. With suitable cost considerations the total supply chain revenue (profit) with respect to decentralized decision and coordination with price discount are derived. By minimizing the total profit the optimal ordering policies of the supply chain are obtained. It is observed that the coordination model is more cost effective compared to the non coordination model.

A sensitivity analysis of the model with respect to the parameters and costs is also included to study the effect of change in input parameters. This model is much useful for scheduling the supply chain of several products in industries dealing with deteriorated items. This model can also be extended for different types of demand at retailer and manufacturer levels which require further investigations.

\section{REFERENCES}

[1] Goyal S K, Giri B C.(2001) "invited review recent trends in modeling of deteriorating inventory". European journal of operational research, 9134, pp 116.

[2] Abdullah Eroglu, gultekin Ozdemir.(2007) "An economic order quantity model with defective items and shortages". International journal of production economics.106 (2), pp 544-549

[3] LUO Jain, QTU Hong-quan, DONG Weiwei(2007). "An EOQ Model for deteriorating items with Backlogging". Mathematics in Practice and Theory, 37(6), pp 6-10

[4] J. Gutierrezs, A. Sedeno-Noda, M.Colebrook, J. Sicilia.(2007), “An efficient approach for solving the lot-sizing problem with time-varying storage capacities". European Journal of Operational Research, vol 189, pp -682-693
[5] Cachon GP (2002), "Supply chain coordination with contracts". Working paper. University of Pennsylvania;

[6] Xuxia Zou, Shaligram Pokharel, Rajesh piplani(2008). "A two-period supply contract model for a decentralized assembly system". European Journal of Operation a Research, (187), pp 257-274

[7] CACHON G P(2004). "The allocation of inventory risk in a supply chain: push, pull, and advance-purchase discount contracts". Management Science, 50(2), pp 222- 239 .

[8] WENG Z K, WONG RT(1993). "General Models for the supplier's all-unit quantity discount policy". Naval Research Logistics, (40), pp 971-991.

[9] ZHAO Quanwu, XIONG Zhongkai, YANG Xiutail, BU Xiangzi(2005). "Study on quantity discounts in a twoechelon supply chain for perishable goods". Journal of Systems Engg, 20(3), pp 318-322.

[10] Chung-Chi Hsieh, Cheng-Han Wu, Ya-Jing Huang (2008). "Ordering and pricing decisions in two-echelon supply chain with asymmetric demand information". European Journal of Operational Research, (190), pp 509-525.

[11] Liao Li, Wu Yaohua, Zhang Danyu, $\mathrm{Hu}$ Hongchun.(2008), "A coordination model of supply chain for deterioration items", international conference on automation and logistics Qingdao, China September.pp 1339-1343.

[12] Yu, Y., Huang, G.Q., \& Liang, L. (2009). Stackelberg game-theoretic model for optimizing advertising,pricing and inventory policies in vendor managed inventory(VMI) production supply chains. Computers and Industrial Engineering, 57, pp 368-382.

[13] Yao, Y., Dong, Y., \& Dresner, M. (2010). Managing supply chain backorders under vendor managed inventory: An incentive approach and empirical analysis,European Journal of operational research, 203(2),pp 350-359. 